
Not for reproduction, distribution or commercial use.

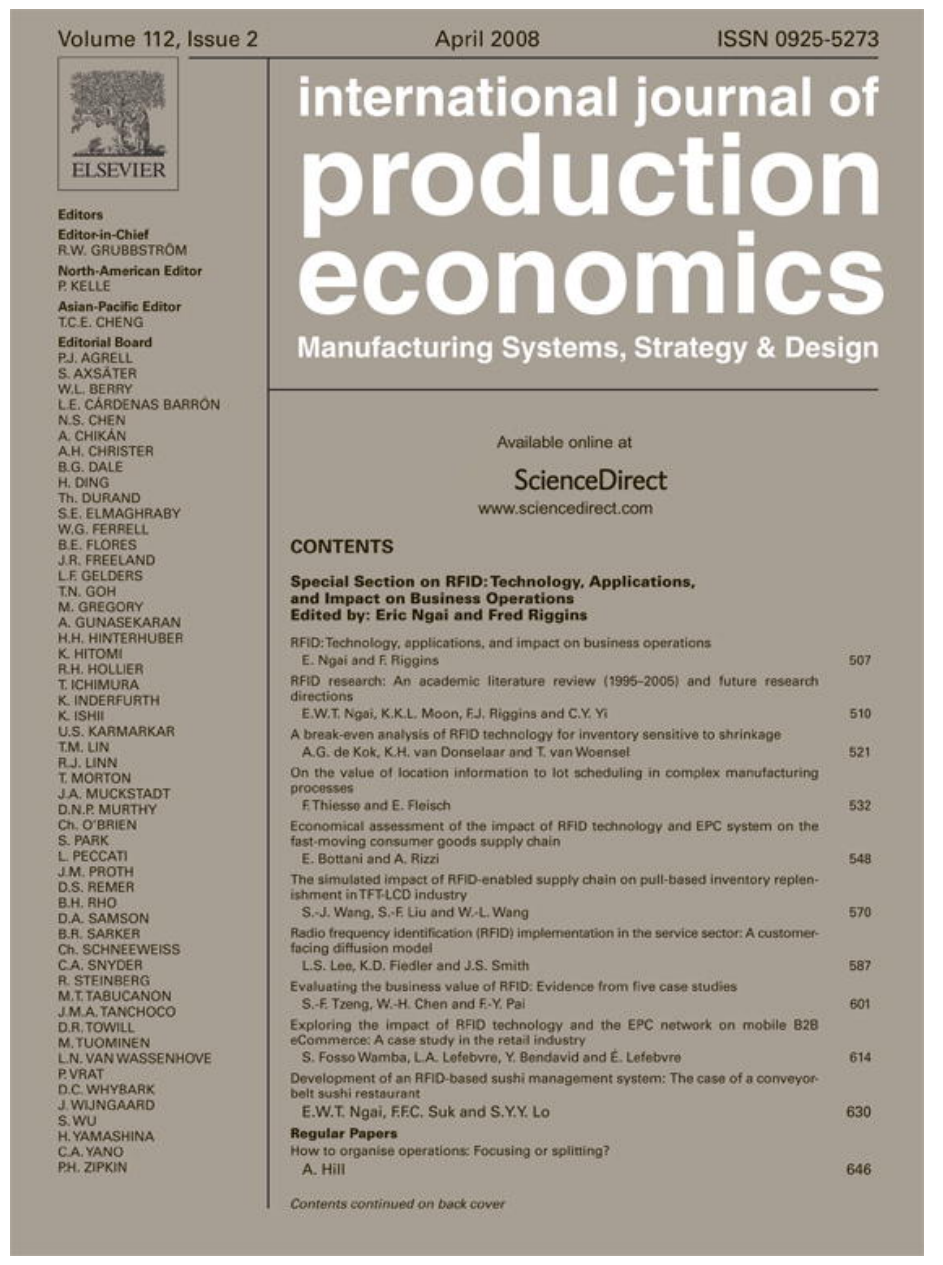

This article was published in an Elsevier journal. The attached copy

is furnished to the author for non-commercial research and education use, including for instruction at the author's institution, sharing with colleagues and providing to institution administration.

Other uses, including reproduction and distribution, or selling or licensing copies, or posting to personal, institutional or third party websites are prohibited.

In most cases authors are permitted to post their version of the article (e.g. in Word or Tex form) to their personal website or institutional repository. Authors requiring further information regarding Elsevier's archiving and manuscript policies are encouraged to visit: 


\title{
On the value of location information to lot scheduling in complex manufacturing processes
}

\author{
Frédéric Thiesse*, Elgar Fleisch \\ Institute of Technology Management, University of St. Gallen, Dufourstrasse 40a, 9000 St. Gallen, Switzerland \\ Received 1 March 2006; accepted 16 December 2006 \\ Available online 9 June 2007
}

\begin{abstract}
This research is concerned with the practical use of real-time location systems (RTLSs) in complex manufacturing processes. Starting from the case example of an RFID-based RTLS implementation in a semiconductor fab, we investigate the value of RTLS information on the locations of physical objects in a production system to the problem of efficient job scheduling. For this purpose, we develop a simplified simulation model that captures the main characteristics of the real manufacturing process and propose a set of RTLS-enabled dispatching rules. Our results indicate that the use of RTLS technology provides the opportunity for new levels of process visibility and control in comparison to conventional material-tracking systems. The benefits that can be drawn from the technology include not only an overall acceleration of the existing process but also an additional efficiency gain through novel dispatching rules that take into account real-time information on the logistic processes on the shop floor.
\end{abstract}

(C) 2007 Elsevier B.V. All rights reserved.

Keywords: RFID; Real-time location systems; Semiconductor manufacturing; Dispatching heuristics

\section{Introduction}

\subsection{Practical relevance}

The technologies of radio frequency identification (RFID) enjoy an enormous interest at the current time, not only from the standpoint of research but also from corporate practice. Enterprises from diverse industries are hoping for solutions to a wide range of management problems through RFID, from simple increases in processing efficiency for the

\footnotetext{
${ }^{*}$ Corresponding author. Tel.: + 41712247243 ; fax: + 41712247301 .

E-mail address: frederic.thiesse@unisg.ch (F. Thiesse).

URL: http://www.item.unisg.ch
}

receipt and dispatch of goods in distribution centres through to improvements in goods availability on the shelves and on to the struggle against shrinkage and product counterfeiting. While the current interest has its base mostly in the advantages of RFID as a technology for automatic identification in comparison with the classical barcode, its very specific characteristics as a radio technology make possible a range of applications for which the barcode appears to be completely unsuitable. An example for the latter class of applications is the implementation of real-time location systems (RTLSs) that make use of RFID signal strength measurements or other sensor information to locate arbitrary physical objects within a given area (Borriello et al., 2005; Hazas et al., 2004; Sorensen, 
2003). In contrast to a sequence of discrete identification events generated by a conventional tracking system, a RTLS provides a continuous stream of location data, which offers the opportunity to visualize and control even weakly structured processes with low automation levels in real time (Piggin and Brandt, 2006). However, the number of research contributions that concern themselves with these issues is still very limited.

Against this background, our contribution investigates the benefits of RTLS use in production logistics. This research is motivated by the authors' experiences with the deployment of an RFID-based RTLS at Infineon Technologies, one of the largest semiconductor manufacturers in the world. Semiconductor wafer fabrication facilities ("wafer fabs") are characterized by heterogeneous parallel machines, a mix of different product types, re-entrant process flows and prescribed customer due dates of the orders (Yan et al., 2000). To address these issues, a range of highly automated transportation systems solutions are being used in practice whose concept mostly addresses the needs of large fabs with relatively static processes, limited product range and high-volume production. In contrast to that, Infineon also operates several fabs that require more flexible, operator-centric automation approaches because of their stronger customer orientation, the large number of varying production processes and frequent rearrangements of the fab's machineries and other technical equipment. For this reason, the company decided to implement a RTLS that combines the flexibility of manual production processes with the high level of visibility and control of conventional automation technologies. The main goals of the project were decreased cycle times, complete prevention of handling faults, as well as the reduction of non-value-adding activities.

\subsection{Research question and methodology}

The aim of this paper is to provide an analysis of the practical benefits of location information in the context of complex production systems. To address this issue, we consider a stylized model of a reentrant manufacturing process, which abstracts the main characteristics of a production system as can be found in wafer fabs. Furthermore, we develop a set of dispatching rules that make use of RTLS data and compare their performance with conventional heuristics via simulation. The underlying hypothesis of this research is that the benefits of RTLS use are twofold: on the one hand, it is evident that precise location information may help to accelerate existing processes by reducing inefficient search activities and their negative impact on overall process performance. On the other hand, we assume that location information can also serve as a foundation for novel dispatching heuristics that further optimize the scheduling of production lots with regard to various performance indicators, e.g. mean cycle time, machine utilization and others.

The remainder of the paper is organized as follows: In Section 1, we provide an overview of related work on dispatching heuristics that are used in semiconductor manufacturing and similar industries. In the following section, we describe the example of a real-world implementation of an RFID-based RTLS for process control in a wafer fab. In order to obtain a better understanding of the impact of the enhanced process visibility resulting from a RTLS, we continue with a description of our simulation model and an analysis of our experimental results. The paper closes with a discussion of the contribution's managerial implications and suggestions for further research.

\section{Related work on dispatching rules}

Techniques used for job scheduling have a significant impact on the performance of semiconductor wafer fabrication (Wein, 1988). Most approaches to the semiconductor manufacturing scheduling problem can be classified into four categories: heuristic dispatching rules, mathematical programming techniques, neighbourhood search methods and artificial intelligence techniques (Gupta and Sivakumar, 2006). While some manufacturers are already using more advanced scheduling procedures, the most common approach to production control problems in practice is still the use of dispatching rules (Dabbas and Fowler, 2003; Rose, 2003). These rules are used to decide what job to schedule next when a machine becomes available. Surveys of such rules can be found in Holthaus and Rajendran (1997), Jain and Meeran (1999), Johri (1993) and Rajendran and Holthaus (1999). Blackstone et al. (1982) conduct a study on widely used dispatching rules. They develop four categories that apply well to the dispatching rules used in the semiconductor industry today. The categories are:

- strategies involving processing time;

- strategies involving due dates; 
- strategies involving neither processing times nor due dates (simple);

- strategies involving two or more of the first three classes (combined).

Shortest processing time (SPT) is an example of a strategy involving processing time and a widely used benchmark rule. SPT ranks lots waiting for a resource according to their processing time at this particular resource. Earliest due date (EDD) is an example of the second category that is also widely used, both in real-life shops as well as in theoretical studies. First in first out (FIFO) is an example of the third category that performs substantially the same as random selection with respect to mean cycle time or mean lateness. Category four denotes combinations of the above-mentioned rules, e.g. in the form of an SPT strategy that switches to FIFO for long waiting queues.

Heuristic rules have strong advantages in that these are easy to understand, easy to apply and require relatively little computing time. The primary disadvantage is that these tend to be myopic in time and space, i.e. they usually use only local information for decision making (Gupta and Sivakumar, 2006). The performance measures that are commonly used to evaluate rules include cycle time (or flow time), machine utilization, throughput rates and inventory levels. Of all these, cycle time is considered a key performance criterion since reducing the cycle time can improve market responsiveness and reduce the inventory level of manufacturing systems such as semiconductor manufacturing (Sivakumar, 1999; Nazzal et al., 2006).

While a large body of research on job scheduling for minimizing cycle times has been published in the past decades, research has only recently focused on the intermediate transport process. Traditional studies of semiconductor manufacturing usually do not regard inter-arrival times at all or model them as an exponentially distributed random variable. Owing to the rise of automated material handling systems (AMHS) in recent years, the control of the transport process now plays an increasingly important role in both theoretical studies and manufacturing practice. Examples of AMHS are automated guided vehicles, overhead hoist transport and continuous flow transport through the use of conveyors (Nazzal and Bodner, 2003). Kuo and Huang (2006) as well as Christopher et al. (2005), for instance, provide analyses of different AMHS dispatching rules, e.g. the nearest job first rule, which selects the nearest lot that waits for transport.

No significant body of published research appears to exist addressing the application of RTLS and similar technologies to manual transport processes in wafer fabs and other complex production systems that are carried out by human operators who are responsible for wafer processing. In this setting, job scheduling at the machine is influenced by the transport process and vice versa, i.e. our analysis investigates machine dispatching rules that make use of location information to improve performance indicators such as the mean cycle time. In contrast to highly automated production systems, the information on a lot's position in the fab is not available due to process standardization and automation technology, but rather due to the use of a RTLS.

\section{Case example}

In this section, we present the example of a realworld implementation of a RTLS that has been in use for more than 2 years in one of Infineon Technologies' wafer fabs and was recently implemented in two other fabs in Europe and Asia. We first give an overview of the difficulties of wafer manufacturing and continue with the system's functionality and practical experiences.

\subsection{Characteristics of fab processes}

The manufacturing of integrated circuits on silicon wafers is a highly complex manufacturing process (Atherton and Atherton, 1995; Dabbas and Fowler, 2003; Johri, 1993; Uzsoy et al., 1992). The production of a medium complexity circuit, for example, requires between 250 and 500 process steps on 50-120 different types of equipment (Mönch et al., 2006). Furthermore, the production process of circuits requires an extremely clean manufacturing area, i.e. usually the production of circuits takes place in cleanroom environments. The increasingly important production of application-specific circuits is additionally characterized by a wide range of product types and the growing demand to meet due dates (Mittler and Schömig, 1999).

In a typical wafer fab, machines of the same type are usually grouped into work centres. A lot visits a work centre more than once, in fact up to 20 times (Mittler and Schömig, 1999). The process flow shows a cyclic pattern with lots of material being 
at different stages of processing, which join in front of this work centre and fork after it, contending with each other for service at this centre. A manufacturing system having this feature is called a re-entrant line (Bispo and Tayur, 2001). Most semiconductor facilities use a job-shop layout for ease of equipment installation, maintenance and flexibility to accommodate process flow changes. This layout configuration and the above-mentioned existence of re-entrant flow cause lots to travel long distances within a relatively small cleanroom area during the process cycle (Pierce and Stafford, 1994).

The fab that we consider in the following is the headquarter of Infineon's Automotive and Industrial Business Group. The unit develops and produces components primarily for use in cars, such as engine management, transmission control, comfort and safety management, and infotainment. The fab operates $24 / 7$ with 2000 employees and manufactures about 800 different products at a total volume of 10 billion chips/year. Owing to the enormous variety of processes, production lots are not transported using AMHS, but carried manually from one of the 600 machines to another. For this purpose, lots are kept in plastic boxes, the so-called "Front Opening Unified Pods" (FOUPs), which contain a wafer cassette that holds up to 25 silicon wafers. These boxes are stored on metal shelves everywhere in the clean room before and after processing. In this manner, an average of about 400 production steps are processed per lot before the integrated circuits can eventually be tested (cf. Fig. 1). The size of the cleanroom area is about $10,000 \mathrm{~m}^{2}$.

In the past, in Infineon's fab, the actual production procedure in a single machine was controlled by the central manufacturing execution system (MES), whereas the intermediate transport process was largely intransparent to the system. Therefore, the correct sequence of production steps could not be properly controlled, which was the root cause for faults during lot processing and unnecessary search times. In some cases operators could not carry out

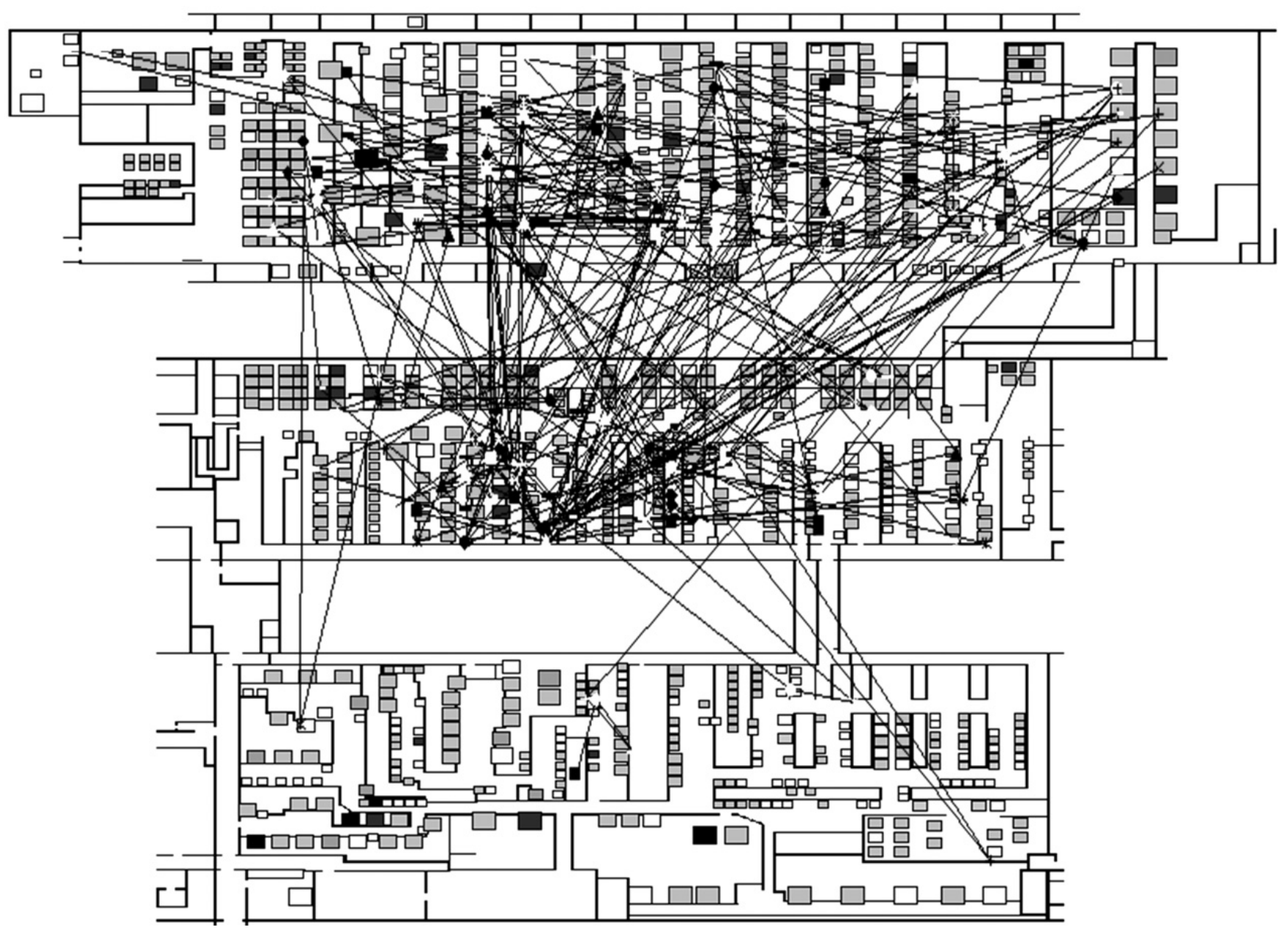

Fig. 1. Example of a single lot's process path through the fab (source: Infineon Technologies). 
the MES's scheduling plan at all since some lots could not be found in time. As a result, operators had to rearrange processing orders on their own account, which had a negative influence on cycle times. Against this background, Infineon Technologies decided to equip the fab with a RTLS in order to make a lot's entire production process visible and thus controllable.

\subsection{RTLS deployment}

In the first project phase, a suitable identification and tracking technology had to be selected. In the case of production lot tracking in a chip fab's clean room, several requirements and constraints had to be taken into account, e.g. the fact that walls, floors and ceilings in the fab are made of metal that can complicate RF communications and also generate electromagnetic reflections. It became clear that the trade-off between high location accuracy and high communication rate together with a large number of wafer carriers could only be resolved by a combination of radio frequency and ultrasound technologies. Active RFID was selected as the foundation for the desired solution mainly because of the battery requirements and communication performance. Owing to insoluble problems with electromagnetic reflections, ultrasound sensors were selected for finegrained tracking.

In the resulting solution concept, ultrasound emitters on the ceiling periodically send a signal that is received by active RFID transponders, which are equipped with ultrasound sensors. The tags calculate the time of flight for all received signals and store these values in their read/write memory. RFID controllers read this data and the lot's identification number from the tags and transfer them to a central server that generates location information for all objects in the system. The server, again, continuously transfers lot locations to the fab's MES. Furthermore, it is responsible not only for lateration calculations but also for plausibility checks and other filtering procedures that guarantee a high level of data quality.

\subsection{Practical use}

Production processes in the fab are organized by means of dispatch lists that contain all waiting lots that must be processed in a specific type of machine ordered by priority. Operators can select the lot they wish to process next directly on screen. The RTLS provides information on its position (e.g. "Aisle A, $2.7 \mathrm{~m}$ ") and the operator can make a LED on the transponder blink so that the carrier can be found very easily. The system also detects whether a wafer carrier is currently at rest or moving, i.e. the operator can decide whether he should wait for the lot to arrive or actively search for it. The operator then picks up the wafer carrier and brings it to a machine. He opens the FOUP, puts the wafer cassette into the machine and starts the processing step. When the processing has finished, the operator takes the cassette out of the machine and puts it back into the carrier. The system automatically moves the lot to another dispatch list. Then the operator puts the box on a shelf where it waits to be transported to another machine.

All in all, location visibility of lots in the fab has increased from $65 \%$ to $100 \%$. The current installation comprises 100 controller devices and more than 1000 RTLS transponders that generate about 3 billion distance measurement messages per day. This huge amount of data is processed and leads to 270 million location data sets. Since the system only publishes position changes that exceed a configurable threshold, the net total of positions delivered to its client systems is 500,000 per day. The time lag between physical movement and the corresponding position message is about $30 \mathrm{~s}$. While ultrasound tracking basically allows for a location accuracy of about $\pm 5 \mathrm{~cm}$ under laboratory conditions, the productive system reaches only $\pm 30 \mathrm{~cm}$. This is owing to the dynamic production environment with several moving people and objects that cause ultrasonic reflections and slightly incorrect distance measurements that are not recognized by the system's plausibility checks. Other factors are background noise from machines that generate noise in the ultrasonic spectrum and discrepancies between reference coordinates in the system database and the real positions of ultrasound emitters.

\section{Simulation model}

The case of Infineon's RTLS implementation is an example of a complex manufacturing process that is supported by real-time information on the location of physical assets. Although the benefit of lot location information in this production system is rather evident, it does not provide answers to the question to what extent RTLS technology bears the potential of enabling novel scheduling approaches 
since the system in the Infineon case is only used to accelerate an existing process. It is against this background that we present a scaled down and simplified model for discrete event-based simulation in this section to test the performance of RTLS-enabled dispatching rules in comparison to traditional heuristics.

Simulation has been the main tool used in research to test different operational decisions in fabs. The reasons for this are the intractability of detailed analytical models of the manufacturing process, the uncertainties inherent in the process itself and the steady improvement in computer technology which makes building simulation models easier and reduces the computational expense of the resulting models (Uzsoy et al., 1992; Kuhl and Laubisch, 2004; Zhou, 1999). In contrast to previous works, we explicitly model the manual transport to a machine as part of a lot's manufacturing process. Owing to the highly individual nature of an operator's behaviour and the lack of precise data on the lot transport process before the RTLS was implemented, parts of the model are approximations based on first-hand experience in the clean room and interviews with operators.

\subsection{Model formulation}

We consider a production system with $G$ machine groups and $M_{g}$ machines per group, $g \in\{1, \ldots, G\}$. All machines in a group are identical and can perform the same processing steps, whereas machines from different groups are not interchangeable. Each machine $m$ of group $g$ has its individual coordinate $p_{g m}$ in the system $m \in\{1, \ldots, M\}$. A machine is surrounded by a number of storage shelves within radius $R$ that are used to store waiting lot carriers between two processing steps. Every machine group has its own entry queue filled with lots that are waiting to be processed at one of the machines in this particular group. The control input policy used in our simulations is "constant WIP" (Wein, 1988), where the amount of work in progress in the system is kept constant and new lots are started only as others are completed. $L_{\max }$ denotes the maximum number of lots in the system.

A particular lot $l$ comprises $S$ different processing steps. By definition, every lot starts at machine group 1, followed by groups 2, 3 and so on. Thus, machine group 1 is visited $\left\lceil\frac{S}{G}\right\rceil$ times and lots at different stages in their manufacturing cycle compete with each other for the same machines.
Step $s$ of lot $l$ is defined by the processing duration $d_{l s}$ and the required machine group $h_{l s}=$ $((s-1) \bmod S)+1 ; s \in\{1, \ldots, S\}$. If $\mathrm{TR}_{l}$ and $\mathrm{TC}_{l}$ denote the time when lot $l$ is released into the system and when it is completed, the total time that the lot spends in a waiting queue or in transit from one machine to another is given by

$\mathrm{TR}_{l}-\mathrm{TC}_{l}-\sum_{s=1}^{S} d_{l s}$

If a processing step $s-1$ has ended, lot $l$ is transported to a shelf that belongs to the nearest machine $m$ of group $h_{l s}$. At this point in time, the lot has not yet been assigned to a specific machine, i.e. machine $m$ is not necessarily the one that the lot will be processed at next. The coordinate of the lot on that shelf is given by $q_{l s}$, with $\left|p_{h_{l s} m}-q_{l s}\right| \leqslant R$. The greater the $R$, the more chaotically are the lots stored in the fab.

As in the real world, lot positions are not known to operators in the fab in advance. In fact, they look for lot carriers with the aid of a RTLS. The system's output for an arbitrary lot position $q_{l s}$ in the system is given by

$v\left(q_{l s}, \gamma\right)= \begin{cases}\left\lfloor\frac{q_{l s}}{\gamma}+\frac{1}{2}\right\rfloor \gamma, & \gamma>0, \\ q_{l s}, & \gamma=0,\end{cases}$

where $v$ denotes the mapping function that locates the lot depending on the RTLS's location accuracy $\gamma$. The smaller the $\gamma$, the more the accuracy with which the tracking system locates objects. $\gamma=0 \mathrm{~m}$ denotes the state of perfect visibility, i.e. the system provides the exact coordinate of any object in the system. $\gamma=2 \mathrm{~m}$, for instance, denotes a location accuracy of $\pm 1 \mathrm{~m}$. The RTLS would accordingly map a lot with coordinates $x=1.3 \mathrm{~m}$ and $y=4.3 \mathrm{~m}$ onto coordinates $x^{*}=2.0 \mathrm{~m}$ and $y^{*}=4.0 \mathrm{~m}$.

Whenever a machine in the system becomes available, the operator starts his search for the highest ranked lot on the dispatch list and transports it to the machine. Our approximation of the transport process in the model is divided into three phases (cf. Fig. 2). In the first phase, the operator walks along a straight line from the machine to the position provided by the RTLS. If $w$ denotes the operator's walking speed, this phase takes

$\frac{\left|v\left(q_{l s}, \gamma\right)-p_{g m}\right|}{w}$

time units. In the second phase, he searches the lot and moves spirally from this position until he finds 
Phase 1: Walking to the designated position

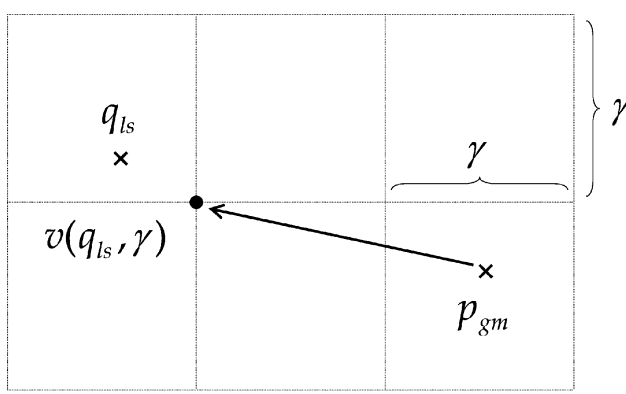

Phase 2: Searching

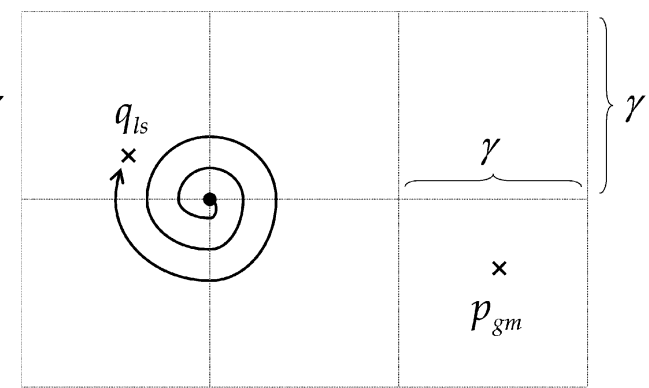

Phase 3: Walking back to the machine

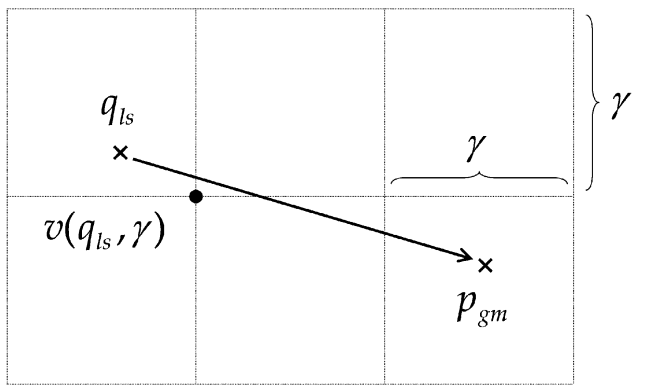

Fig. 2. Phases of the transport process.

the lot. If the radius of the spiral increases by $\delta$ per rotation, this phase takes

$\frac{\left|q_{l s}-v\left(q_{l s}, \gamma\right)\right|}{\delta} \frac{4 \pi\left|q_{l s}-v\left(q_{l s}, \gamma\right)\right|}{2 w}=\frac{4 \pi\left(\left|q_{l s}-v\left(q_{l s}, \gamma\right)\right|\right)^{2}}{2 w \delta}$

time units. Note that $\delta$ can be interpreted as the efficiency of the operator's search process, i.e. the greater the $\delta$, the faster the lot will be found. In the third phase, he walks back to the machine. This phase takes

$\frac{\left|q_{l s}-p_{g m}\right|}{w}$

time units. The total transport time $t$ is thus given by

$$
\begin{aligned}
& t\left(q_{l s}, p_{g m}, \gamma\right) \\
& \quad=\frac{2 \delta\left(\left|v\left(q_{l s}, \gamma\right)-p_{g m}\right|+\left|q_{l s}-p_{g m}\right|\right)+4 \pi\left(\left|q_{l s}-v\left(q_{l s}, \gamma\right)\right|\right)^{2}}{2 w \delta} .
\end{aligned}
$$

While this transport process might seem very simplistic at first glance, it nevertheless features the characteristics of a real search that we are interested in within the context of our analysis. On the one hand, the duration for a straight walk to a known position increases linearly with the distance. On the other hand, the time to search a particular area increases quadratically with its radius. The location accuracy of the tracking system has therefore a significant impact on the efficiency of the transport process.

\subsection{Dispatching rules}

The purpose of our model is to test the performance of RTLS-enabled dispatching rules and to compare them with conventional rules that do not make use of any location information. Owing to the broad range of different rules that can be found in academic contributions, we focus on a small selection of rules that can often be found in practice, namely the classical FIFO rule as well as two other rules that prioritize lots based on processing times. Furthermore, we present a novel rule that makes use of estimated transport times. By the end of the section, we also discuss the combination of location information with other rules.

\subsection{1. $\mathrm{FIFO/-}$}

This rule is an adaptation of the well-known FIFO rule, which simply ignores the fact that transport times can be long if the operator has no information on a lot's current location. Under this rule, the operator always processes the highest ranked lot even if he has to search the entire shop floor to obtain it. 


\subsection{2. $\mathrm{FIFO} / \mathrm{NV}$}

This rule is another adaptation of the FIFO rule, but, in contrast to FIFO/-, it takes into account that lot locations are not known to the operator. Under the $\mathrm{FIFO} / \mathrm{NV}$ rule, the operator first searches shelves within radius $R$ that are associated to the available machine and selects the highest ranked lot that he finds. The operator extends his search only if no lot could be found in the first search.

\subsection{3. $\mathrm{FIFO} / \mathrm{V}$}

This rule is a third FIFO adaptation, but, in contrast to the previous two variants, FIFO/V makes use of location information provided by a RTLS. Under this rule, the operator gets the location of the first lot in the waiting queue from the RTLS and brings it to the available machine for processing according to the described transport process.

\subsection{4. $S P T / V$}

SPT/V equals the classic SPT rule with additional visibility over lot locations, i.e. the lots in the waiting queue are ordered by their processing time at the particular machine. Analogously to FIFO/V, the operator gets the location of the highest ranked lot in the queue from the RTLS and brings it to the machine for processing according to the described transport process. Conway and Maxwell (1962) note that the SPT rule can lead to extraordinarily long waiting times for individual jobs. Therefore, $\mathrm{SPT} / \mathrm{V}$ is based on a truncated SPT rule (Fry et al., 1988) that switches to FIFO/V for lots with long waiting times.

\subsection{5. $S R P T / V$}

This rule is another example of a rule that prioritizes lots by their processing times. In contrast to $\mathrm{SPT} / \mathrm{V}$, this rule considers not only a lot's following processing step but also the entire sequence of remaining steps. The operator selects the lot with the shortest remaining processing time and brings it to the available machine according to the described transport process. Analogously to $\mathrm{SPT} / \mathrm{V}, \mathrm{SRPT} / \mathrm{V}$ switches to FIFO/V for lots with long waiting times.

\subsection{6. $S T T / V$}

The STT/V rule is not an adaptation of any conventional rule, but rather relies on estimated transport times $t^{\prime}$ that can be calculated as follows:

$t^{\prime}\left(q_{l s}, p_{g m}, \gamma\right)=2 \frac{\left|v\left(q_{l s}, \gamma\right)-p_{g m}\right|}{w}$.

For $\gamma=0$, the estimation evidently equals the real transport time. The operator selects the lot with the shortest transport time and brings it to the machine for processing according to the described transport process. Analogously to SPT/V, STT/V switches to FIFO/V for lots with long waiting times.

\subsection{7. $S R P T / V+$}

This rule is a combination of SRPT/V and $\mathrm{STT} / \mathrm{V}$. In contrast to SRPT/V, this rule ranks lots by the sum of their remaining processing times and their estimated transport time:

$\sum_{i=s}^{S} d_{l i}+2 \frac{\left|v\left(q_{l s}, \gamma\right)-p_{g m}\right|}{w}$

i.e. the rule tends to prefer lots that are likely to be located close to the available machine in order to avoid long transport processes.

\subsubsection{Other rules}

The use of location information with other dispatching rules is relatively straightforward and follows the same pattern as the above-mentioned RTLS-enabled rules. EDD/V (EDD), for instance, would prioritize lots by the sum of the lot's estimated transport time and the respective due date. $\mathrm{CR} / \mathrm{V}$ (critical ratio) would accordingly consider the ratio between a lot's remaining processing time and the remaining available time minus the transport time.

\section{Experimental results}

In this section, we present results of a series of simulation experiments that we conducted with the proposed dispatching rules. Our simulation model was implemented in C\#.NET and tested with alternative pseudo-random generators to make sure that the built-in generator does not lead to bias in the simulation results. The statistical analysis was done with MS Access and MS Excel.

The summary of our results starts with the base case given in Table 1 and continues with a sensitivity analysis of various model parameters. In order to reduce complexity and prevent excessive running times, the values were chosen to equal about $1 / 10$ of the characteristics of a real fab. 
We assume that the duration of a processing step $d_{l s}$ is normally distributed. Furthermore, we assume that storage shelves are uniformly distributed across a machine's environment within radius $R$, which is an approximation based on our observations in the clean room. The same holds for the values that characterize the operator's search process, which are estimations as well.

Table 1

Parameter values for the base case

\begin{tabular}{|c|c|c|}
\hline Parameter & Value & Description \\
\hline$G$ & 5 & Number of machine groups \\
\hline$M$ & 5 & Number of machines per group \\
\hline$L_{\max }$ & 200 & $\begin{array}{l}\text { Maximum number of lots in the } \\
\text { system }\end{array}$ \\
\hline$S$ & 20 & Number of processing steps per lot \\
\hline$\mu$ & $10 \mathrm{~min}$ & Mean duration of a processing step \\
\hline$\sigma$ & $1 \mathrm{~min}$ & Variance in processing durations \\
\hline$R$ & $5 \mathrm{~m}$ & $\begin{array}{l}\text { Maximum distance between } \\
\text { machines and shelves }\end{array}$ \\
\hline$w$ & $1 \mathrm{~m} / \mathrm{s}$ & Walking speed \\
\hline$\delta$ & $1 \mathrm{~m}$ & Efficiency of the search process \\
\hline
\end{tabular}

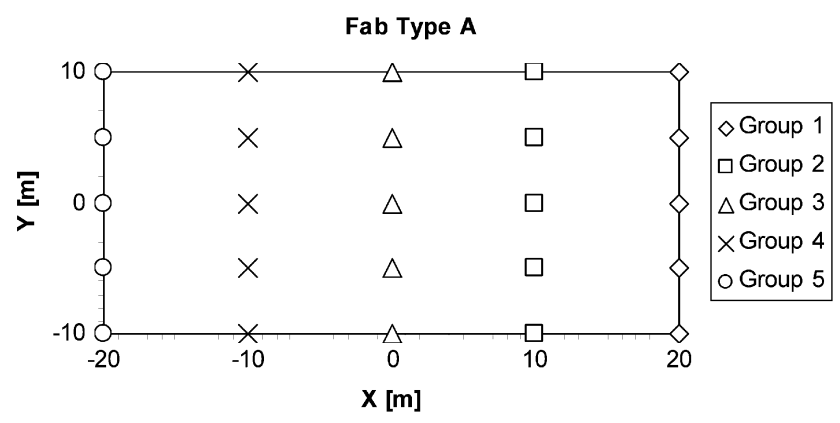

The dimensions of the simulated production system in the base case are $40 \times 20 \mathrm{~m}^{2}$ (cf. Fig. 3). Since the maximum distance between two arbitrary machines in the fab is $\sqrt{40^{2}+20^{2}}=44.72$ and the maximum distance between a storage shelf and a machine is $R=5$, it is evident that location accuracies $\gamma>49.72$ have no effect on the performance of our system. Therefore, our simulations for different $\gamma$ are limited to the interval $[0,50]$.

The wafer fab is a non-terminating production system and to simulate it accurately a warm-up period should be allowed. At the beginning of a simulation run, we fill the system with the first $L_{\max }$ lots and release additional lots only if another lot is completed. The sample size was set to 1000 jobs. Based on the technique developed by Welch (1983), we decided to truncate the first $2 L_{\max }$ lots in order to make sure that our sample reflects the system in a steady state. Furthermore, the system was kept in a steady state until every lot of the 1000 lots had left it to avoid the problem of "censored data" (Blackstone et al., 1982). We ran 30 replications for each parameter setting.

\subsection{Impact of RTLS accuracy}

In the first step of our analysis, we separately investigate the impact of process visibility on a lot's waiting, transport and processing time on the basis of the three FIFO rules. We ran simulations of the FIFO/V rule for different RTLS accuracies $0 \leqslant \gamma \leqslant 50$ and used FIFO/- and FIFO/NV as a benchmark. The results are depicted in Fig. 4.

It is evident from the structure of our model that lot dispatching has no influence on a lot's processing

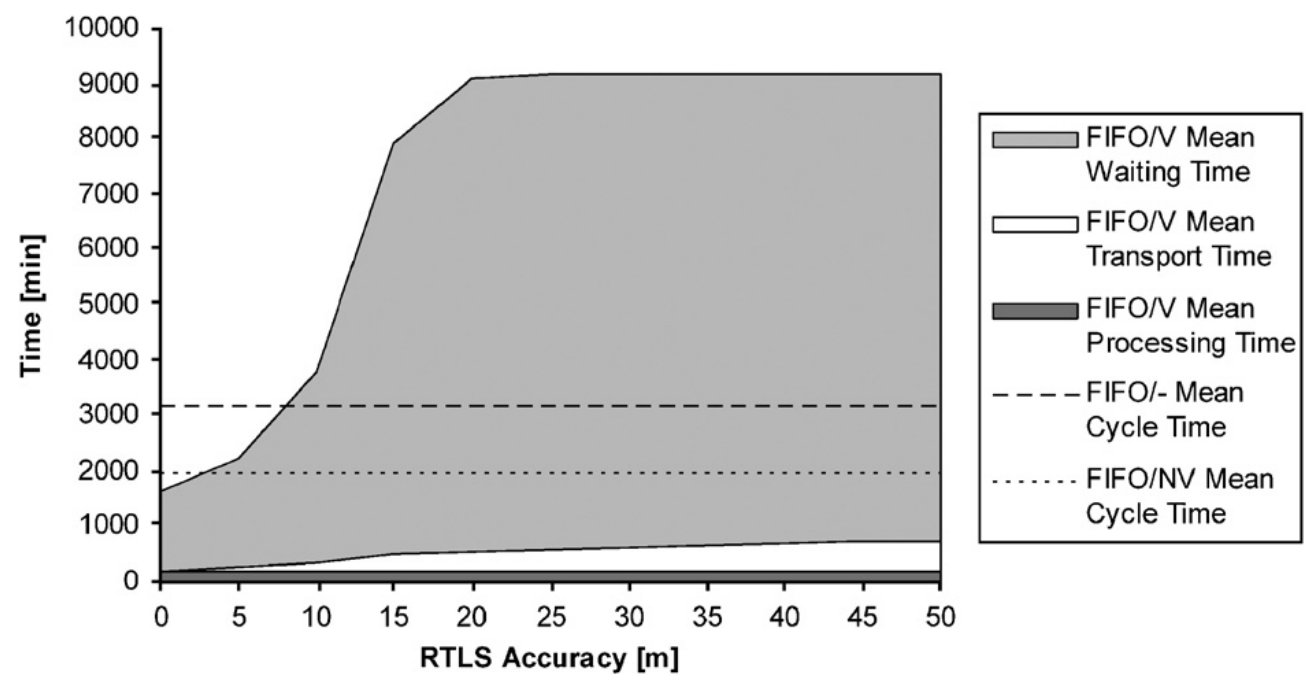

Fig. 4. FIFO/V waiting, transport and processing times. 
times and remains constant for different $\gamma$ since all machines of a particular group are identical. In contrast to that, transport times are significantly improving with better RTLS accuracies. Over and above, the substantial decrease of waiting times that leads to dramatically reduced total cycle times. This result can be explained by the fact that machines are blocked for other lots while the operator looks for one specific lot carrier. Thus, the reduction of a lot's transport times has the same impact on cycle times as a decrease of processing times, and eventually leads to a reduction of waiting times for all succeeding lots in the queue. An overview of simulation results of waiting, transport and processing times for various $\gamma$ is given in Table 2 .

Table 2

Comparison of waiting, transport and processing times for FIFO rules

\begin{tabular}{lrrrll}
\hline \multirow{2}{*}{ Rule } & $\gamma$ & \multicolumn{5}{l}{ Mean cycle time (min) } \\
\cline { 3 - 6 } & & Waiting & Transport & Processing & $\Sigma$ \\
\hline FIFO/- & - & 2764.05 & 214.20 & 200.27 & 3178.52 \\
FIFO/NV & - & 1707.87 & 57.78 & 200.27 & 1965.92 \\
FIFO/V & 0 & 1428.14 & 5.82 & 200.27 & 1634.23 \\
& 1 & 1451.03 & 8.03 & 200.27 & 1659.33 \\
& 2 & 1522.35 & 14.47 & 200.27 & 1737.08 \\
& 3 & 1639.37 & 24.89 & 200.27 & 1864.52 \\
& 4 & 1801.76 & 39.11 & 200.27 & 2041.14 \\
& 5 & 1988.25 & 54.02 & 200.27 & 2242.54 \\
& 10 & 3410.04 & 163.04 & 200.27 & 3773.35 \\
20 & 8538.34 & 353.50 & 200.27 & 9092.11 \\
30 & 8570.64 & 422.18 & 200.27 & 9193.10 \\
40 & 8463.46 & 521.88 & 200.27 & 9185.61 \\
50 & 8427.14 & 548.70 & 200.27 & 9176.11 \\
\hline
\end{tabular}

\subsection{Comparison of RTLS-enabled rules}

In the second step of our analysis, we compared the performance of the five RTLS-enabled dispatching rules. As depicted in Fig. 5, location accuracies of at least about $\pm 2 \mathrm{~m}$ are necessary to outperform the FIFO/NV rule; $\gamma \geqslant 8 \mathrm{~m}$ even leads to worse results than the rudimentary $\mathrm{FIFO} /-$ rule, i.e. a RTLS with bad location accuracy leads to less efficient process performance than no visibility at all.

A more detailed overview of simulation results is given in Table 3. Besides the mean cycle time, we also consider the mean machine utilization ratio as a second performance indicator that is defined as follows:

mean processing time

mean transport time + mean processing time

As can be seen from these results, the combination of processing and transport times in the form of the SRPT $/ \mathrm{V}+$ rule achieves the best performance with regard to cycle times. For $\gamma=0$, this rule significantly outperforms FIFO/V, with $47.67 \%$ vs. $51.42 \%$ in comparison to $\mathrm{FIFO} /-$. However, the better average values come with the disadvantage of more variance. In contrast to that, STT/V achieves the best results with regard to machine utilization. Owing to the fact that STT/V aims to minimize transport times, it minimizes a machine's idle times as well. For $\gamma=0$, this rule $(98.92 \%)$ outperforms both FIFO/V (97.18\%) and $\mathrm{SRTP} / \mathrm{V}+(97.43 \%)$.

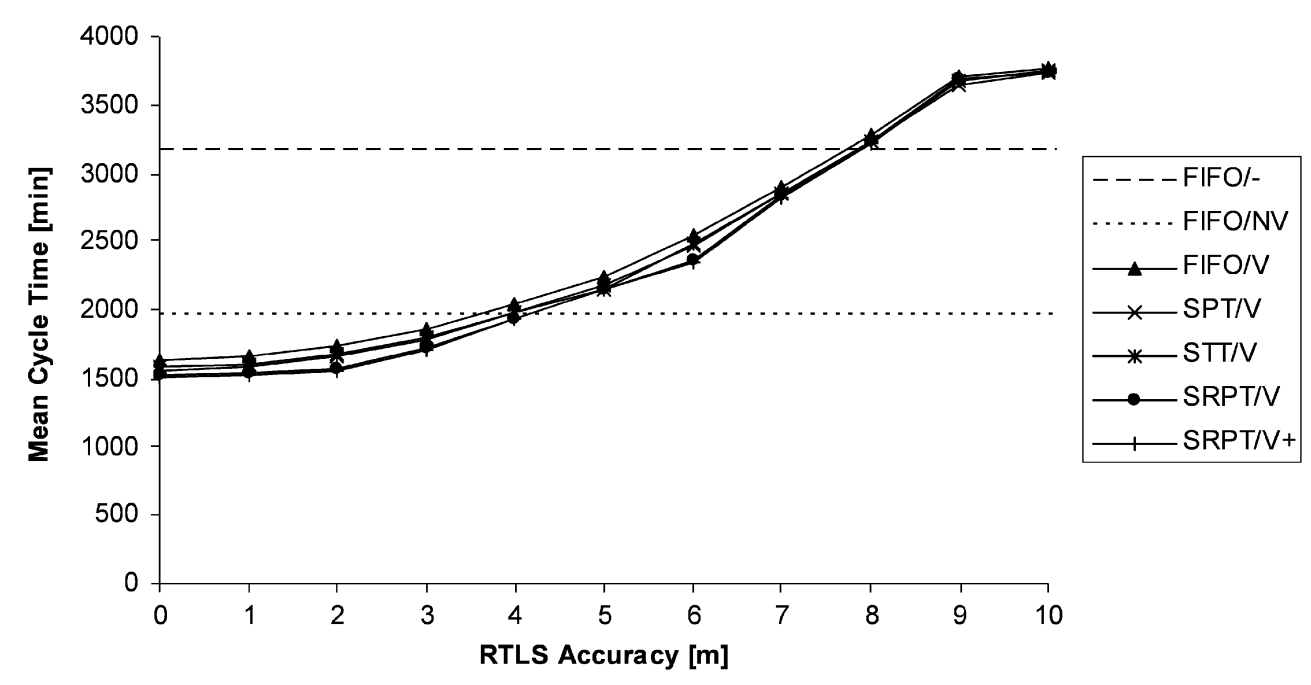

Fig. 5. Comparison of dispatching rules for different RTLS accuracies. 
Table 3

Comparison of dispatching rules for different RTLS accuracies

\begin{tabular}{|c|c|c|c|c|c|c|c|c|}
\hline \multirow[t]{2}{*}{ Rule } & \multirow[t]{2}{*}{$\gamma$} & \multirow[t]{2}{*}{ Min } & \multicolumn{3}{|c|}{ Mean cycle time } & \multicolumn{3}{|c|}{ Mean machine utilization } \\
\hline & & & $\%$ & SD & $\mathrm{CI}$ & $\%$ & SD & $\mathrm{CI}$ \\
\hline $\mathrm{FIFO} /-$ & - & 3178.52 & 100.00 & 0.00 & 0.00 & 48.32 & 0.26 & 0.10 \\
\hline $\mathrm{FIFO} / \mathrm{NV}$ & - & 1965.92 & 61.85 & 0.63 & 0.23 & 77.61 & 0.25 & 0.09 \\
\hline \multirow[t]{5}{*}{ FIFO/V } & 0 & 1634.23 & 51.42 & 0.52 & 0.19 & 97.18 & 0.02 & 0.01 \\
\hline & 1 & 1659.33 & 52.21 & 0.54 & 0.20 & 96.14 & 0.03 & 0.01 \\
\hline & 2 & 1737.08 & 54.65 & 0.55 & 0.21 & 93.26 & 0.06 & 0.02 \\
\hline & 5 & 1864.52 & 58.66 & 0.64 & 0.24 & 88.95 & 0.09 & 0.03 \\
\hline & 10 & 2041.14 & 64.22 & 0.60 & 0.23 & 83.66 & 0.14 & 0.05 \\
\hline \multirow[t]{5}{*}{$\mathrm{SPT} / \mathrm{V}$} & 0 & 1582.46 & 49.79 & 1.14 & 0.43 & 97.18 & 0.02 & 0.01 \\
\hline & 1 & 1605.80 & 50.52 & 1.41 & 0.53 & 96.14 & 0.02 & 0.01 \\
\hline & 2 & 1677.94 & 52.79 & 1.47 & 0.55 & 93.26 & 0.05 & 0.02 \\
\hline & 5 & 1803.04 & 56.73 & 1.46 & 0.54 & 88.93 & 0.09 & 0.03 \\
\hline & 10 & 1978.97 & 62.26 & 1.33 & 0.50 & 83.65 & 0.14 & 0.05 \\
\hline \multirow[t]{5}{*}{$\mathrm{STT} / \mathrm{V}$} & 0 & 1556.92 & 48.98 & 0.74 & 0.28 & 98.92 & 0.16 & 0.06 \\
\hline & 1 & 1592.81 & 50.11 & 0.78 & 0.29 & 97.79 & 0.16 & 0.06 \\
\hline & 2 & 1664.12 & 52.36 & 0.75 & 0.28 & 94.51 & 0.12 & 0.05 \\
\hline & 5 & 1786.06 & 56.19 & 0.73 & 0.27 & 89.87 & 0.10 & 0.04 \\
\hline & 10 & 1986.19 & 62.49 & 1.09 & 0.41 & 84.41 & 0.14 & 0.05 \\
\hline \multirow[t]{5}{*}{ SRPT/V } & 0 & 1529.87 & 48.14 & 2.20 & 0.82 & 97.18 & 0.02 & 0.01 \\
\hline & 1 & 1539.22 & 48.43 & 2.26 & 0.84 & 96.15 & 0.02 & 0.01 \\
\hline & 2 & 1567.56 & 49.32 & 1.81 & 0.68 & 93.26 & 0.05 & 0.02 \\
\hline & 5 & 1718.99 & 54.08 & 1.26 & 0.47 & 88.93 & 0.09 & 0.03 \\
\hline & 10 & 1939.10 & 61.01 & 1.45 & 0.54 & 83.66 & 0.14 & 0.05 \\
\hline \multirow[t]{5}{*}{$\mathrm{SRPT} / \mathrm{V}+$} & 0 & 1515.07 & 47.67 & 2.32 & 0.87 & 97.43 & 0.03 & 0.01 \\
\hline & 1 & 1524.77 & 47.98 & 2.21 & 0.82 & 96.39 & 0.03 & 0.01 \\
\hline & 2 & 1552.54 & 48.85 & 1.74 & 0.65 & 93.48 & 0.05 & 0.02 \\
\hline & 5 & 1711.73 & 53.85 & 1.31 & 0.49 & 89.15 & 0.09 & 0.03 \\
\hline & 10 & 1936.71 & 60.93 & 1.42 & 0.53 & 83.87 & 0.14 & 0.05 \\
\hline
\end{tabular}

$\mathrm{SD}=$ standard deviation, $\mathrm{CI}=$ confidence interval at $95 \%$ significance level.

\subsection{Sensitivity analysis}

In the third step, we conducted a sensitivity analysis in order to obtain a better understanding of the positive or negative influence of particular model parameters on the performance of RTLSenabled dispatching rules. We consider both fabspecific (fab layout, fab size, distance between machines and shelves) as well as lot-specific parameters (work in progress, number of processing steps and variance processing times). We tested each parameter setting with the three FIFO rules and the best-performing rule from the base case, i.e. $\mathrm{SRPT} / \mathrm{V}+$.

\subsubsection{Fab layout}

In order to investigate the influence of machine positions, we developed four additional fab layouts that differ from the original layout (Fab Type A) in the base case (cf. Fig. 6). Type B denotes a transposed version of Type A with larger distances between identical machines and smaller distances between machine groups. Type $\mathrm{C}$ denotes a fab with clustered machine groups. In contrast to that, Type $\mathrm{D}$ includes clusters with one machine of each group. Lastly, Type E denotes a random layout that we generated for each replication.

The results of our simulations with different fab layouts are summarized in Table 4. As one can see, Type B leads to a worse performance of the FIFO/rule since the operator has to travel longer distances in his search for a particular lot, whereas the results for the other rules remain virtually constant. In contrast to that, Type $\mathrm{C}$ leads to much better results for $\mathrm{FIFO} /-$ due to the small distance between identical machines. For the same reason, FIFO/NV performs even worse than $\mathrm{FIFO} /$ - since the rule forces the operator to concentrate on one machine 

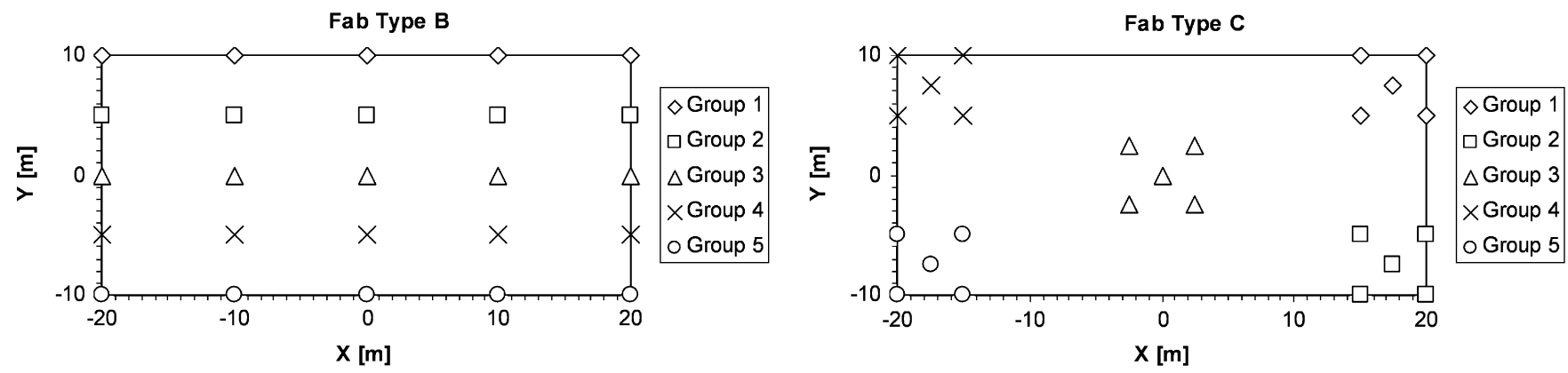

Fab Type D
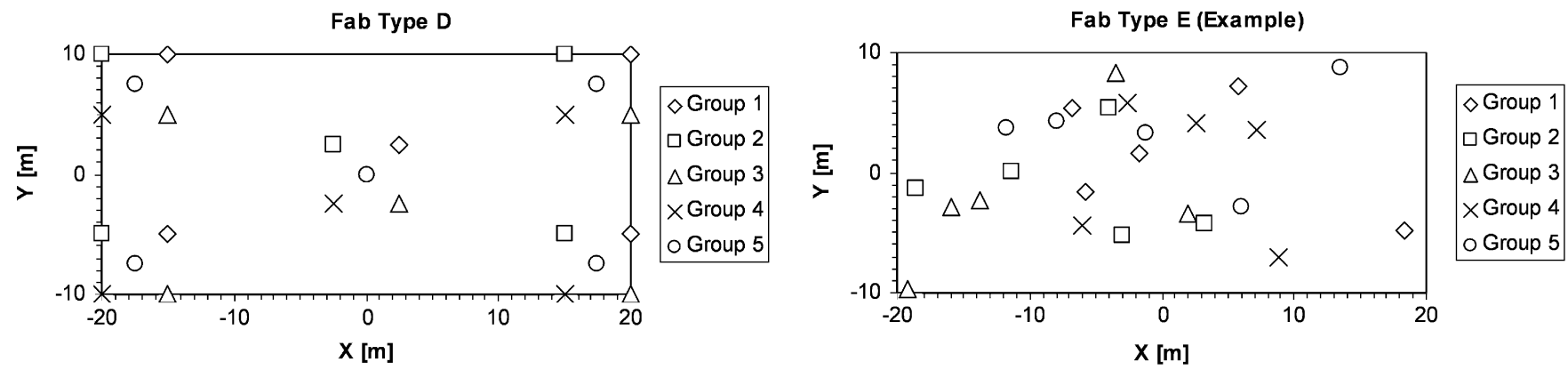

Fig. 6. Fab layout variations.

Table 4

Comparison of dispatching rules for different fab layouts

\begin{tabular}{|c|c|c|c|c|c|c|c|c|}
\hline \multirow[t]{2}{*}{ Fab layout } & \multirow[t]{2}{*}{ Rule } & \multirow[t]{2}{*}{ Min } & \multicolumn{3}{|c|}{ Mean cycle time } & \multicolumn{3}{|c|}{ Mean machine utilization } \\
\hline & & & $\%$ & SD & CI & $\%$ & SD & CI \\
\hline \multirow[t]{4}{*}{ Type A } & FIFO/- & 3178.52 & 100.00 & 0.00 & 0.00 & 48.32 & 0.26 & 0.10 \\
\hline & $\mathrm{FIFO} / \mathrm{NV}$ & 1965.92 & 61.85 & 0.63 & 0.23 & 77.61 & 0.25 & 0.09 \\
\hline & FIFO/V & 1634.23 & 51.42 & 0.52 & 0.19 & 97.18 & 0.02 & 0.01 \\
\hline & $\mathrm{SRPT} / \mathrm{V}+$ & 1515.07 & 47.67 & 2.32 & 0.87 & 97.43 & 0.03 & 0.01 \\
\hline \multirow[t]{4}{*}{ Type B } & FIFO/- & 7433.97 & 100.00 & 0.00 & 0.00 & 20.69 & 0.12 & 0.05 \\
\hline & $\mathrm{FIFO} / \mathrm{NV}$ & 1966.72 & 26.46 & 0.35 & 0.13 & 77.81 & 0.49 & 0.18 \\
\hline & $\mathrm{FIFO} / \mathrm{V}$ & 1674.61 & 22.53 & 0.30 & 0.11 & 94.76 & 0.03 & 0.01 \\
\hline & $\mathrm{SRPT} / \mathrm{V}+$ & 1549.26 & 20.84 & 0.97 & 0.36 & 95.34 & 0.05 & 0.02 \\
\hline \multirow[t]{4}{*}{ Type C } & FIFO/- & 2068.17 & 100.00 & 0.00 & 0.00 & 76.33 & 0.12 & 0.05 \\
\hline & $\mathrm{FIFO} / \mathrm{NV}$ & 2431.20 & 117.56 & 1.54 & 0.58 & 65.29 & 0.14 & 0.05 \\
\hline & FIFO/V & 1614.79 & 78.08 & 0.43 & 0.16 & 98.37 & 0.01 & 0.00 \\
\hline & $\mathrm{SRPT} / \mathrm{V}+$ & 1499.30 & 72.50 & 3.35 & 1.25 & 98.42 & 0.01 & 0.00 \\
\hline \multirow[t]{4}{*}{ Type D } & FIFO/- & 10633.06 & 100.00 & 0.00 & 0.00 & 14.57 & 0.14 & 0.05 \\
\hline & FIFO/NV & 2401.31 & 22.58 & 0.29 & 0.11 & 63.84 & 0.72 & 0.27 \\
\hline & $\mathrm{FIFO} / \mathrm{V}$ & 1697.93 & 15.97 & 0.21 & 0.08 & 93.50 & 0.04 & 0.01 \\
\hline & $\mathrm{SRPT} / \mathrm{V}+$ & 1570.01 & 14.77 & 0.77 & 0.29 & 94.23 & 0.08 & 0.03 \\
\hline \multirow[t]{4}{*}{ Type E } & FIFO/- & 6679.33 & 100.00 & 0.00 & 0.00 & 31.41 & 5.65 & 2.11 \\
\hline & $\mathrm{FIFO} / \mathrm{NV}$ & 3829.12 & 60.06 & 15.51 & 5.79 & 43.62 & 5.92 & 2.21 \\
\hline & FIFO/V & 1664.51 & 26.43 & 6.31 & 2.36 & 95.69 & 0.46 & 0.17 \\
\hline & $\mathrm{SRPT} / \mathrm{V}+$ & 1519.99 & 24.15 & 5.87 & 2.19 & 95.98 & 0.42 & 0.16 \\
\hline
\end{tabular}

$\mathrm{SD}=$ standard deviation, $\mathrm{CI}=$ confidence interval at $95 \%$ significance level.

even though other machines of the same group are not far away. Type D results in the worst performance of the FIFO/- rule, whereas the two
RTLS-enabled rules are virtually not affected. For layouts of Type $\mathrm{E}$, again, the FIFO/NV rule provides the worst performance of all considered layouts. 
Table 5

Comparison of dispatching rules for different fab sizes

\begin{tabular}{|c|c|c|c|c|c|c|c|c|}
\hline \multirow[t]{2}{*}{ Fab size $\left(\mathrm{m}^{2}\right)$} & \multirow[t]{2}{*}{ Rule } & \multirow[t]{2}{*}{ Min } & \multicolumn{3}{|c|}{ Mean cycle time } & \multicolumn{3}{|c|}{ Mean machine utilization } \\
\hline & & & $\%$ & $\mathrm{SD}$ & $\mathrm{CI}$ & $\%$ & $\mathrm{SD}$ & $\mathrm{CI}$ \\
\hline \multirow[t]{4}{*}{$10 \times 5$} & FIFO/- & 1702.71 & 100.00 & 0.00 & 0.00 & 93.13 & 0.07 & 0.03 \\
\hline & FIFO/NV & 1568.79 & 92.14 & 0.43 & 0.16 & 97.45 & 0.36 & 0.13 \\
\hline & FIFO/V & 1600.09 & 93.97 & 0.15 & 0.06 & 99.28 & 0.01 & 0.00 \\
\hline & $\mathrm{SRPT} / \mathrm{V}+$ & 1485.86 & 87.27 & 4.19 & 1.57 & 99.34 & 0.01 & 0.00 \\
\hline \multirow[t]{4}{*}{$20 \times 10$} & FIFO/- & 2011.44 & 100.00 & 0.00 & 0.00 & 78.00 & 0.18 & 0.07 \\
\hline & FIFO/NV & 1649.66 & 82.02 & 0.47 & 0.18 & 92.54 & 0.34 & 0.13 \\
\hline & FIFO/V & 1611.64 & 80.12 & 0.27 & 0.10 & 98.57 & 0.01 & 0.00 \\
\hline & $\mathrm{SRPT} / \mathrm{V}+$ & 1495.78 & 74.37 & 3.45 & 1.29 & 98.69 & 0.01 & 0.00 \\
\hline \multirow[t]{4}{*}{$40 \times 20$} & $\mathrm{FIFO} /-$ & 3178.52 & 100.00 & 0.00 & 0.00 & 48.32 & 0.26 & 0.10 \\
\hline & FIFO/NV & 1965.92 & 61.85 & 0.63 & 0.23 & 77.61 & 0.25 & 0.09 \\
\hline & FIFO/V & 1634.23 & 51.42 & 0.52 & 0.19 & 97.18 & 0.02 & 0.01 \\
\hline & $\mathrm{SRPT} / \mathrm{V}+$ & 1515.07 & 47.67 & 2.32 & 0.87 & 97.43 & 0.03 & 0.01 \\
\hline \multirow[t]{4}{*}{$80 \times 40$} & FIFO/- & 7811.41 & 100.00 & 0.00 & 0.00 & 19.71 & 0.18 & 0.07 \\
\hline & FIFO/NV & 3222.20 & 41.26 & 0.56 & 0.21 & 47.33 & 0.22 & 0.08 \\
\hline & FIFO/V & 1679.88 & 21.51 & 0.29 & 0.11 & 94.51 & 0.04 & 0.02 \\
\hline & $\mathrm{SRPT} / \mathrm{V}+$ & 1550.36 & 19.85 & 0.95 & 0.35 & 95.05 & 0.05 & 0.02 \\
\hline \multirow[t]{4}{*}{$160 \times 80$} & FIFO/- & 26073.26 & 100.00 & 0.00 & 0.00 & 5.92 & 0.07 & 0.03 \\
\hline & FIFO/NV & 8291.40 & 31.80 & 0.44 & 0.16 & 18.40 & 0.10 & 0.04 \\
\hline & FIFO/V & 1768.59 & 6.78 & 0.09 & 0.03 & 89.61 & 0.07 & 0.02 \\
\hline & $\mathrm{SRPT} / \mathrm{V}+$ & 1628.88 & 6.25 & 0.30 & 0.11 & 90.81 & 0.10 & 0.04 \\
\hline
\end{tabular}

$\mathrm{SD}=$ standard deviation, $\mathrm{CI}=$ confidence interval at $95 \%$ significance level.

\subsubsection{Fab size}

A second parameter that we considered in our sensitivity analysis was the total fab size. It is evident from the search process that larger areas favour RTLS-enabled rules. This expectation is confirmed by the results in Table 5 .

\subsubsection{Work in progress}

Table 6 summarizes our simulation results for different values of $L_{\max }$. The figures indicate that the number of lots that are processed simultaneously in the production system have virtually no influence on the relative advantage of the RTLSenabled rules over $\mathrm{FIFO} /-$. In contrast to that, FIFO/NV improves with decreasing $L_{\max }$ because the operator more often finds the highest prioritized lot near the available machine if waiting queues are small.

\subsubsection{Distance between machines and shelves}

Radius $R$ can be interpreted as a parameter that determines how chaotically lot carriers are stored on the fab area. Large values of $R$ indicate that the operator has to search larger areas in order to find a specific lot that is assigned to a particular machine. As the results in Table 7 indicate, the two RTLSenabled rules can cope much better with chaotic behaviour than their conventional counterparts, whereas $\mathrm{FIFO} / \mathrm{NV}$ performs significantly worse for increasing $R$.

\subsubsection{Processing time}

In order to investigate the influence of the variance of processing times, we ran simulations for different $\sigma$ ranging from $30 \mathrm{~s}$ to $2 \mathrm{~min}$. Our results indicate that these parameter changes have no significant influence on process performances at all.

\subsubsection{Processing steps}

We conducted simulations for different values of $S$ in order to verify whether the number of processing steps has any influence on process performance indicators. As expected, the results show that cycle times grow linearly with $S$, whereas the relative differences between the rules remain virtually constant. The only observable effect that could be found was a slight but not significant 
Table 6

Comparison of dispatching rules for different $L_{\max }$

\begin{tabular}{|c|c|c|c|c|c|c|c|c|}
\hline \multirow[t]{2}{*}{$L_{\max }$} & \multirow[t]{2}{*}{ Rule } & \multirow[t]{2}{*}{ Min } & \multicolumn{3}{|c|}{ Mean cycle time } & \multicolumn{3}{|c|}{ Mean machine utilization } \\
\hline & & & $\%$ & SD & $\mathrm{CI}$ & $\%$ & SD & $\mathrm{CI}$ \\
\hline \multirow[t]{4}{*}{50} & $\mathrm{FIFO} /-$ & 824.08 & 100.00 & 0.00 & 0.00 & 48.23 & 0.27 & 0.10 \\
\hline & $\mathrm{FIFO} / \mathrm{NV}$ & 638.28 & 77.45 & 0.46 & 0.17 & 60.65 & 0.28 & 0.10 \\
\hline & FIFO/V & 407.96 & 49.51 & 0.40 & 0.15 & 97.18 & 0.02 & 0.01 \\
\hline & $\mathrm{SRPT} / \mathrm{V}+$ & 398.36 & 48.34 & 0.38 & 0.14 & 97.29 & 0.02 & 0.01 \\
\hline \multirow[t]{4}{*}{100} & FIFO/- & 1604.93 & 100.00 & 0.00 & 0.00 & 48.26 & 0.23 & 0.09 \\
\hline & $\mathrm{FIFO} / \mathrm{NV}$ & 1011.23 & 63.01 & 0.50 & 0.19 & 75.62 & 0.30 & 0.11 \\
\hline & $\mathrm{FIFO} / \mathrm{V}$ & 817.16 & 50.92 & 0.49 & 0.18 & 97.18 & 0.02 & 0.01 \\
\hline & $\mathrm{SRPT} / \mathrm{V}+$ & 773.99 & 48.23 & 0.84 & 0.32 & 97.36 & 0.03 & 0.01 \\
\hline \multirow[t]{4}{*}{200} & FIFO/- & 3178.52 & 100.00 & 0.00 & 0.00 & 48.32 & 0.26 & 0.10 \\
\hline & $\mathrm{FIFO} / \mathrm{NV}$ & 1965.92 & 61.85 & 0.63 & 0.23 & 77.61 & 0.25 & 0.09 \\
\hline & $\mathrm{FIFO} / \mathrm{V}$ & 1634.23 & 51.42 & 0.52 & 0.19 & 97.18 & 0.02 & 0.01 \\
\hline & $\mathrm{SRPT} / \mathrm{V}+$ & 1515.07 & 47.67 & 2.32 & 0.87 & 97.43 & 0.03 & 0.01 \\
\hline \multirow[t]{4}{*}{400} & FIFO/- & 6410.35 & 100.00 & 0.00 & 0.00 & 48.31 & 0.36 & 0.13 \\
\hline & $\mathrm{FIFO} / \mathrm{NV}$ & 3902.41 & 60.88 & 0.72 & 0.27 & 78.22 & 0.19 & 0.07 \\
\hline & FIFO/V & 3263.96 & 50.92 & 0.55 & 0.21 & 97.18 & 0.02 & 0.01 \\
\hline & $\mathrm{SRPT} / \mathrm{V}+$ & 3043.58 & 47.49 & 3.61 & 1.35 & 97.52 & 0.03 & 0.01 \\
\hline \multirow[t]{4}{*}{800} & $\mathrm{FIFO} /-$ & 12955.64 & 100.00 & 0.00 & 0.00 & 48.23 & 0.26 & 0.10 \\
\hline & $\mathrm{FIFO} / \mathrm{NV}$ & 7779.35 & 60.05 & 0.49 & 0.18 & 78.39 & 0.17 & 0.06 \\
\hline & $\mathrm{FIFO} / \mathrm{V}$ & 6518.75 & 50.32 & 0.44 & 0.16 & 97.18 & 0.02 & 0.01 \\
\hline & $\mathrm{SRPT} / \mathrm{V}+$ & 6326.14 & 48.83 & 4.32 & 1.61 & 97.62 & 0.03 & 0.01 \\
\hline
\end{tabular}

$\mathrm{SD}=$ standard deviation, $\mathrm{CI}=$ confidence interval at $95 \%$ significance level.

Table 7

Comparison of dispatching rules for different $R$

\begin{tabular}{|c|c|c|c|c|c|c|c|c|}
\hline \multirow[t]{2}{*}{$S$} & \multirow[t]{2}{*}{ Rule } & \multirow[t]{2}{*}{ Min } & \multicolumn{3}{|c|}{ Mean cycle time } & \multicolumn{3}{|c|}{ Mean machine utilization } \\
\hline & & & $\%$ & SD & $\mathrm{CI}$ & $\%$ & SD & $\mathrm{CI}$ \\
\hline \multirow[t]{4}{*}{5} & $\mathrm{FIFO} /-$ & 3048.83 & 100.00 & 0.00 & 0.00 & 50.10 & 0.19 & 0.07 \\
\hline & $\mathrm{FIFO} / \mathrm{NV}$ & 1569.97 & 51.50 & 0.48 & 0.18 & 97.32 & 0.45 & 0.17 \\
\hline & $\mathrm{FIFO} / \mathrm{V}$ & 1631.09 & 53.50 & 0.48 & 0.18 & 97.36 & 0.02 & 0.01 \\
\hline & $\mathrm{SRPT} / \mathrm{V}+$ & 1512.15 & 49.60 & 2.34 & 0.87 & 97.64 & 0.02 & 0.01 \\
\hline \multirow[t]{4}{*}{10} & FIFO/- & 3069.15 & 100.00 & 0.00 & 0.00 & 49.73 & 0.24 & 0.09 \\
\hline & $\mathrm{FIFO} / \mathrm{NV}$ & 1647.38 & 53.68 & 0.46 & 0.17 & 92.72 & 0.40 & 0.15 \\
\hline & $\mathrm{FIFO} / \mathrm{V}$ & 1631.81 & 53.17 & 0.43 & 0.16 & 97.30 & 0.02 & 0.01 \\
\hline & $\mathrm{SRPT} / \mathrm{V}+$ & 1513.20 & 49.31 & 2.36 & 0.88 & 97.58 & 0.03 & 0.01 \\
\hline \multirow[t]{4}{*}{20} & FIFO/- & 3178.52 & 100.00 & 0.00 & 0.00 & 48.32 & 0.26 & 0.10 \\
\hline & $\mathrm{FIFO} / \mathrm{NV}$ & 1965.92 & 61.85 & 0.63 & 0.23 & 77.61 & 0.25 & 0.09 \\
\hline & $\mathrm{FIFO} / \mathrm{V}$ & 1634.23 & 51.42 & 0.52 & 0.19 & 97.18 & 0.02 & 0.01 \\
\hline & $\mathrm{SRPT} / \mathrm{V}+$ & 1515.07 & 47.67 & 2.32 & 0.87 & 97.43 & 0.03 & 0.01 \\
\hline \multirow[t]{4}{*}{40} & FIFO/- & 3646.49 & 100.00 & 0.00 & 0.00 & 42.24 & 0.20 & 0.07 \\
\hline & FIFO/NV & 3224.35 & 88.43 & 0.54 & 0.20 & 47.40 & 0.17 & 0.06 \\
\hline & FIFO/V & 1641.26 & 45.01 & 0.41 & 0.15 & 96.77 & 0.02 & 0.01 \\
\hline & $\mathrm{SRPT} / \mathrm{V}+$ & 1521.54 & 41.73 & 2.07 & 0.77 & 96.99 & 0.03 & 0.01 \\
\hline \multirow[t]{4}{*}{80} & FIFO/- & 5457.24 & 100.00 & 0.00 & 0.00 & 28.31 & 0.12 & 0.04 \\
\hline & $\mathrm{FIFO} / \mathrm{NV}$ & 8449.11 & 154.83 & 1.26 & 0.47 & 18.08 & 0.07 & 0.03 \\
\hline & FIFO/V & 1660.28 & 30.43 & 0.38 & 0.14 & 95.62 & 0.02 & 0.01 \\
\hline & $\mathrm{SRPT} / \mathrm{V}+$ & 1536.62 & 28.16 & 1.40 & 0.52 & 95.80 & 0.03 & 0.01 \\
\hline
\end{tabular}

$\mathrm{SD}=$ standard deviation, $\mathrm{CI}=$ confidence interval at $95 \%$ significance level. 
improvement of SRPT $/ \mathrm{V}+$ for a small number of processing steps.

\section{Conclusions and outlook}

Conventional tracking systems on the foundation of barcode labels, RFID transponders or other auto-id technologies have been successfully used in transportation and production logistics for many years (see Roberti (2005) for an example of an RFID-based tracking system in a wafer fab). The practical application of these systems presumes that the respective business processes are adequately standardized and sometimes also requires the implementation of additional automation technology. In contrast to that, location systems provide seamless information on the physical world even if processes are highly unstructured and supported by little or no automation. The case of Infineon Technologies provides a practical example of such an application area with many process and product variants, extensive manual activities and a large number of physical objects in a complex production system.

The managerial implications that can be drawn from our research are twofold. Firstly, we have shown that-depending on the technology's capabilities in the form of different location accuracies - the use of a RTLS can lead to significant improvements with regard to process performance indicators such as cycle time, machine utilization, etc. Companies interested in the implementation of a RTLS must be aware of the trade-off between the potential benefits of process visibility and the costs of hardware components and system integration. The Infineon case is an example of a closed-loop process in a high-tech industry that is used for substantial investments in new technologies, i.e. the costs of RTLS technology play a minor role in comparison to the value of the tracked goods. Other companies with different applications will in many cases come to the conclusion that coarse-grained location information at lower costs makes more sense to their requirements from an economical perspective. Secondly, our research indicates that the potential of RTLS technology is not limited to process acceleration, but rather includes the opportunity to develop entirely new heuristics for process control that were not feasible before.

Beyond the above-mentioned operational aspects, RTLS technology can also be of strategic relevance since it offers the unique opportunity of combining the flexibility of unguided manual processes with the process control capabilities of traditional automation technology. Production flexibility in the form of the ability to coordinate and to control a broad number of process variants at low costs poses an important strategic advantage in a highly competitive and customer-driven market. In the case of Infineon's RTLS implementation, a lot of training and change management was necessary to exploit the benefits of the integration of the enriched information quality of an accurate, reliable position of each lot with the existing manufacturing system. First, operators had to learn how to use the system in their working environment. Second, a lot of time had to be spent on optimizing logistics processes and adjusting the entire production automation system.

Our results could be a starting point for future research in various directions. On the one hand, the effects that we have observed need to be verified with the use of more complex models of various types of production systems. On the other hand, we see great potential in the development of process control procedures that make use of identification technologies, location sensing and other sensor data on the physical processes on the shop floor. Not least, models for economical evaluation are needed in order to make substantiated decisions on the value of location accuracy that could justify the investments in a technical object-tracking infrastructure.

\section{Acknowledgements}

The authors wish to thank Markus Dierkes (Intellion) and Hanspeter Fischer (Infineon Technologies) for their support in preparing this paper.

\section{References}

Atherton, L.F., Atherton, R.W., 1995. Wafer Fabrication: Factory Performance and Analysis. Kluwer Academic Publishers, Boston.

Bispo, C.F., Tayur, S., 2001. Managing simple re-entrant flow lines: Theoretical foundation and experimental results. IIE Transactions 33 (8), 609-623.

Blackstone, J.H., Phillips, D.T., Hogg, G.L., 1982. A state-ofthe-art survey of dispatching rules for manufacturing job shop operations. International Journal of Production Research 20 (1), 27-45.

Borriello, G., Chalmers, M., LaMarca, A., Nixon, P., 2005. Delivering real-world ubiquitous location systems. Communications of the ACM 48 (3), 36-41.

Christopher, J., Kuhl, M.E., Hirschmann, K., 2005. Simulation analysis of dispatching rules for automated material handling 
systems and processing tools in semiconductor fabs. In: Proceedings of the IEEE International Symposium on Semiconductor Manufacturing, San Jose, pp. 84-87. URL: $\langle$ http://www.rit.edu/ mekeie/ChristopherKuhlHirschman2005. pdf $\rangle$.

Conway, R.W., Maxwell, W.L., 1962. Network dispatching by the shortest-operation discipline. Operations Research 10 (1), $51-73$.

Dabbas, R.M., Fowler, J.W., 2003. A new scheduling approach using combined dispatching criteria in wafer fabs. IEEE Transactions on Semiconductor Manufacturing 16 (3), 501-510.

Fry, T.D., Philipoom, P.R., Blackstone, J.H., 1988. A simulation study of processing time dispatching rules. Journal of Operations Management 7 (4), 77-92.

Gupta, A.K., Sivakumar, A.I., 2006. Job shop scheduling techniques in semiconductor manufacturing. International Journal of Advanced Manufacturing Technology 27 (11-12), 1163-1169.

Hazas, M., Scott, J., Krumm, J., 2004. Location-aware computing comes of age. IEEE Computer 37 (2), 95-97.

Holthaus, O., Rajendran, C., 1997. Efficient dispatching rules for scheduling in a job shop. International Journal of Production Economics 48 (1), 87-105.

Jain, A.S., Meeran, S., 1999. Deterministic job-shop scheduling: Past, present and future. European Journal of Operational Research 113 (2), 390-434.

Johri, P.K., 1993. Practical issues in scheduling and dispatching in semiconductor wafer fabrication. Journal of Manufacturing Systems 12 (6), 474-485.

Kuhl, M.E., Laubisch, G.R., 2004. A simulation study of dispatching rules and rework strategies in semiconductor manufacturing. In: Proceedings of the 2004 IEEE/SEMI Advanced Semiconductor Manufacturing Conference, Piscataway, pp. 325-329. URL: 〈http://www.rit.edu/ mekeie/ KuhlLaubisch.pdf $>$.

Kuo, C., Huang, C., 2006. Dispatching of overhead hoist vehicles in a fab intrabay using a multimission-oriented controller. International Journal of Advanced Manufacturing Techno$\operatorname{logy} 27$ (7-8), 824-832.

Mittler, M., Schömig, A.K., 1999. Comparison of dispatching rules for semiconductor manufacturing using large facility models. In: Proceedings of the 31st Winter Simulation Conference, Phoenix, pp. 709-713. URL: 〈http://www. informs-cs.org/wsc99papers/101.PDF $>$.

Mönch, L., Schabacker, R., Pabst, D., Fowler, J.W., 2006. Genetic algorithm-based subproblem solution procedures for a modified shifting bottleneck heuristic for complex job shops. European Journal of Operational Research 177 (3), 2100-2118.

Nazzal, D., Bodner, D.A., 2003. A simulation-based design framework for automated material handling systems in $300 \mathrm{~mm}$ fabrication facilities. In: Proceedings of the 35th
Winter Simulation Conference, New Orleans, pp. 1351-1359. URL: 〈http://www.informs-cs.org/wsc03papers/169.pdf〉.

Nazzal, D., Mollaghasemi, M., Anderson, D., 2006. A simulation-based evaluation of the cost of cycle time reduction in Agere Systems wafer fabrication facility-A case study. International Journal of Production Economics 100 (2), 300-313.

Pierce, N.G., Stafford, R., 1994. Modeling and simulation of material handling for semiconductor wafer fabrication. In: Proceedings of the 1994 Winter Simulation Conference, Orlando, pp. 900-906. URL: 〈http://portal.acm.org/ft_ gateway.cfm $? \mathrm{id}=194621 \&$ type $=$ pdf\&coll $=$ GUIDE $\& \mathrm{dl}=$ $\&$ CFID $=15151515 \&$ CFTOKEN $=6184618>$.

Piggin, R., Brandt, D., 2006. Wireless ethernet for industrial applications. Assembly Automation 26 (3), 205-215.

Rajendran, C., Holthaus, O., 1999. A study on the performance of scheduling rules in buffer-constrained dynamic flowshops and jobshops. European Journal of Operational Research 116 (1), 156-170.

Roberti, M., 2005. Ultimate control: RFID-enabled manufacturing. RFID Journal November/December, 28-33.

Rose, O., 2003. Accelerating products under due-date oriented dispatching rules in semiconductor manufacturing. In: Proceedings of the 35th Winter Simulation Conference, New Orleans, pp. 1346-1350. URL: 〈http://www.informs-cs.org/ wsc03papers/168.pdf $>$.

Sivakumar, A.I., 1999. Optimization of a cycle time and utilization in semiconductor test manufacturing using simulation based, on-line, near-real-time scheduling system. In: Proceedings of the 31st Winter Simulation Conference, Phoenix, pp. 727-735. URL: 〈http://www.informs-sim.org/ wsc99papers/104.PDF $>$.

Sorensen, H., 2003. The science of shopping. Marketing Research 15 (3), 30-35.

Uzsoy, R., Lee, C.Y., Martin-Vega, L.A., 1992. A review of production planning and scheduling models in the semiconductor industry, Part I: System characteristics, performance evaluation and production planning. IIE Transactions on Scheduling and Logistics 24 (4), 47-61.

Wein, L., 1988. Scheduling semiconductor wafer fabrication. IEEE Transactions on Semiconductor Fabrication 1 (3), 115-130.

Welch, P.D., 1983. The statistical analysis of simulation results. In: Lavenberg, S. (Ed.), The Computer Performance Modeling Handbook. Academic Press, New York, pp. 268-328.

Yan, H., Sheldon, L., Sethi, S.P., 2000. Robustness of various production control policies in semiconductor manufacturing. Production and Operations Management 9 (2), 171-183.

Zhou, M.C., 1999. Modeling, analysis, simulation, scheduling, and control of semiconductor manufacturing systems: A Petri net approach. IEEE Transactions on Semiconductor Manufacturing 11 (3), 333-357. 